Verbündete in der Forschung 


\section{Internationale Reihe}

des Zentralinstituts für Geschichte der Akademie der Wissenschaften der DDR

Materialien eines Kolloquiums

des Forschungsbereiches Gesellschaftswissenschaften

der Akademie der Wissenschaften der DDR und der Kommission der Historiker der DDR und der UdSSR

4.-5. Juni 1975 in Berlin 


\section{Verbündete in der \\ Forschung}

Traditionen der

deutsch-sowjetischen Wissenschaftsbeziehungen und die wissenschaftliche Zusammenarbeit zwischen der

Akademie der Wissenschaften der UdSSR und der

Akademie der Wissenschaften der DDR

Wissenschaftliche Redaktion:

Peter Altner, Wolfgang Büttner

und Conrad Grau (Leitung)

Akademie-Verlag · Berlin 1976 
Erschienen im Akademie-Verlag, 108 Berlin, Leipziger Str. 3-4

(C) Akademie-Verlag, Berlin 1976

Lizenznummer : $202 \cdot 100 / 371 / 76$

Karte: P 64/76

Gesamtherstellung: IV/2/14 VEB Druckerei

"Gottfried Wilhelm Leibniz",

445 Gräfenhainichen · 4760

Einbandgestaltung: R. Kunze

Bestellnummer: 7530594 (2169/3) · LSV 0245

Printed in GDR

DDR 30,- M 